\title{
Technology meets Psychology: Teaching Business Students Critical Thinking within New Learning Formats
}

\author{
Petra Hauptfeld \\ University of Applied Sciences Burgenland, Austria
}

\begin{abstract}
With the increasing use of technology in education, one may ask if psychological subjects with a huge amount of personal involvement are suitable for teaching within technology based learning formats. The UAS Burgenland redesigned the course "Critical Thinking" for part-time business students to reflect on leadership and intercultural communication using a blended learning format. This paper (presentation) elaborates on the requirements when teaching psychological topics and combining on-campus training with virtual classrooms. Succeeding in this effort means selecting very specific exercises and tasks in the diverse phases, linking them properly, adjusting the feedback processes and being aware of the diverse roles as a coach and moderator. Results have shown that students value the combination of various teaching methods as long as they feel safe within their self-development. Moreover, they are motivated to participate in virtual classrooms as the physical distance provides them with a sense of security in contrast to on-campus classes. The course "Critical Thinking" aims to provide a model for teaching psychological subjects within technology based education.
\end{abstract}

Keywords: innovation, technology, education, e-learning JEL classification: A20

\section{The course "Critical Thinking"}

Within the BA study degree program "International Business Relations" at the UAS Burgenland, part time students who do not complete an internship abroad are obliged to attend the course "Critical Thinking" instead. Under the old format, the course took place in the $1^{\text {st }}, 2^{\text {nd }}, 3^{\text {rd }}$ and $5^{\text {th }}$ semesters for a total of 11 ECTS and no online phases. The aim of the course was to provide students with diverse tools and strategies for metacognition in order to reflect on the contents of their studies and to apply them to their workplace. Several lecturers were involved in teaching, covering topics such as dilemma analysis, work-life-balance, cooperative coaching methods and intercultural communication. This gave the course the image of an irrelevant but compulsory add-on within other subjects like accountancy, financing or foreign trade.

The approach caused several problems. Mainly students in the $5^{\text {th }}$ semester were opposed to the course due to their perception of "wasted time" at the end of their studies when writing their final theses. Some students gave feedback that lecturers or topics turned out to be too personal within the context of the studies; some students performed well and liked the issues, some others did not. Another problem was that business students are not used to metacognition or are not capable of self-reflection at all, so the purpose of the course was not understood. As part time business students are very much driven by reality and pragmatics, reflecting on internal 
mental processes seems to be quite insignificant. So the dichotomy of what the students perceived as useful and what they saw as intellectual had to be resolved.

\section{Redesigning the course within the p.learning strategy}

This situation led us to the question of how we could redesign the course according to the needs of the students and the requirements of the curriculum within the reaccreditation process of the BA program in 2017.

\section{Changing the format}

Firstly, we decided that the course should follow the approach of the "personalized learning strategy" (p.learning strategy) within the institutional strategy 2025 that puts the student in the center of the educational process. This seems more than appropriate for psychological topics on the one hand and ties together the needs of the students and the course contents. The p.learning strategy combines individual settings of students with innovative methods and technology that gives the student the chance to learn according to their own pace. This self-paced learning (Khan, 2013) was enhanced by the implementation of e-learning within the new format.

The new format includes three learning phases that can be linked as needed, which gives the educator and the students the chance to work in a more individualized manner to guarantee, for instance, privacy. One phase is characterized by contact hours, another phase takes place online in virtual classrooms and a third phase includes self-study periods. For the educator, this means framing the teaching according to these three phases by applying tools and using didactical formats appropriately.

In order to support educators in their didactical efforts within this p.learning strategy, the UAS Burgenland started a pilot project called "Regional Competence Center for E-Learning in Province Burgenland". Following a standardized survey on the status quo of personalized teaching activities among the UAS' department staff, it is producing virtual learning materials under the perspective of the research question of how technology can be used to create variable contents for collaborative learning in communities.

Concerning the time schedule, the course was rearranged. The lectures now take place in the first half of the study $\left(1^{\text {st }}, 2^{\text {nd }}\right.$ and $3^{\text {rd }}$ semester with 9 ECTS) during an entire year, starting in January/February ( $1^{\text {st }}$ semester), continuing in May/June (2nd semester) and ending in October/November (3rd semester). The adapted time structure allows a gradual progress where the single on-line and on-campus lectures are connected via the topics. After the redesign, the topics follow a common thread and have been developed by one person (the author) who is also in charge of the other lecturers teaching in parallel groups. This means quite a huge amount of organization but it is worth the effort, as the course now is perceived as an entire unit with a clear concept throughout one year.

\section{Making sense again}

In order to generate meaning for the students, the metacognition process had to be implemented within the topics of study in the utmost possible way. As the students are supposed to be managers in the region of Central Eastern Europe, it was decided to concentrate on two topics and to link them together: reflecting on leadership on the one hand and its influence on intercultural situations on the other hand. Thus we made it very explicit to the students. Since the course is also intended as an equivalent to the internships abroad for full time students, the topic also makes 
sense within the curriculum. It has to be clearly demonstrated to the students that the course is NOT about leadership - it is about reflecting on leadership and situations within an intercultural environment to strive for success.

Following this approach, the course provides the three levels of contents, methods and competencies. The contents are based on information about intercultural issues, the methods serve as a kind of detour (or bridge) towards reflection and the competencies at least concentrate on critical thinking about the results gathered by the applied methods. In doing so, it is easier for students to bridge the gap between useful knowledge and intellectual analysis. They are guided through this process and not confronted at the very beginning of the $1^{\text {st }}$ semester with techniques in critical thinking. Reflecting on internal mental processes needs constant awareness and one may not like what he or she is finding or is struggling with behavior, so a guided process is recommended, embedded within topics that make sense and provide security through accepted items ("leadership").

The contents of the $1^{\text {st }}$ semester incorporated personal and cultural belief systems and how they influence personality and the perception of cultures. Students gain insight into several cultural dimension models and reflect on dilemma situations and controversial texts dealing with a cultural topic. They get used to metacognition through these "external" materials before confronting themselves with personal issues. As a second step, they have to interview a migrant living in Austria according to guided interviews; which problems s/he faced, how s/he succeeded to integrate and which kind of strategies s/he applied within this process. The interviewee should explain what s/he thinks about this process of integration, and therefore figures as a model for reflection. The students are then asked: "What do YOU think about the interviewee's approach?" The results were impressive. During presentations in the oncampus-classes a rich discussion emerged and it was observable how students tried to maintain or change their worldviews. When working with controversial texts one group gave feedback that they discussed it for a long time, even searching for statistics on some facts. Learning took place through feedback processes from others on own perspectives and own feedback on others' thoughts, coming from peer grading (Dräger et.al., 2015). The students at the end of the $1^{\text {st }}$ semester course had to deliver papers then of about 8 pages but they were an average of 12 to 15 pages long. This seemingly shows that there is an extensive need for exchange and reflection, it only depends on how one introduces and stimulates this process.

The $2^{\text {nd }}$ semester, starting in May 2017, will follow this approach by reversing the process and interviewing managers who were expatriates in a CEE country. The students are asked to work with the critical incidents technique by Flanagan. The interviewee has to describe a situation that happed abroad and was critical in the sense that the behavior of the person from the other culture could not be "codified". As a result, communication was not successful. The students then have to analyze which different cultural standards, developed by Alexander Thomas, could have determined this situation. Moreover, they have to work on a solution by using the standards. Again, the manager is asked what he or she thought of the situation as a pre-step for the students' reflection on it, but in contrast to the $1^{\text {st }}$ semester, the topic of leadership is addressed here. The students are then asked what it MEANS to live and work abroad and how companies could prepare employees for the time abroad, starting with their own needs and expectations. Coming from this, they have to develop a set of requirements a company has to fulfill to prepare employees for a workplace abroad.

The $3^{\text {rd }}$ semester, starting in October 2017, will connect the competencies of the former semesters by reflecting on intercultural team communication and leadership. 
As the students are used to metacognition now, they will reflect on personal situations and what they think they can improve. Issues on intercultural team communication and project management as well as communication concepts will be discussed with a focus on personal development. Students have to work on their own case studies and give feedback to others via coaching which requires empathy and changes of perspectives. Again, cultural standards and dimensions play an important role as well as the personal and cultural belief systems influencing them. Students have to write an essay, describing the personal case study, incorporating the reflection from the other students in it and commenting on these reflections. To be able to question diverse perspectives (one's own and those of others), to extend the individual flexibility and to be critical against defined worldviews should be the aim of the entire course. This is what metacognition within the business studies context is able to achieve.

\section{Results on the first semester course}

Implementing the three phases of the educational process within the p.learning strategy, on-campus classes, virtual classrooms and self-study periods required very specific exercises, tools and attitudes. Moreover, "Critical Thinking" cannot be squeezed into a subject but is a lifelong endeavor. The $1^{\text {st }}$ semester course had to consider this approach in order to give students a sense for personal development. In contrast, when a given subject has been sealed, wrapped, and tied up with a bow and if the message is that the subject is finished, why bother to remember it? Especially when dealing with psychological issues, the "subject" is the person itself and not the amount of teaching hours. Following this approach the course provides the three levels of contents, methods and competencies within the three phases and the educator has to be able to didactically frame these phases by choosing the tasks properly under the aspect of best implementation in each phase.

In the $1^{\text {st }}$ semester course the phases were linked together as follows: the influence of intercultural dimensions and belief systems on leadership was explained in class by a short lecture, combined with additional exercises to make sure that the necessity of "Critical Thinking" within a managerial education is not a luxury good but an inevitable asset. Moreover, the educator elaborated on the methodology of the guided interview technique and the tasks for the virtual classroom in the traditional role of a teacher, instructing the students. Within the virtual classroom, the educator's role changed into the one as a moderator, assisting the students by giving feedback on the interview guidelines they had to prepare and giving advice on certain questions of the guidelines. It turned out that a discussion started on the topic of how personal one question might be. Thus, the process of reflection already started here by assuming that touchy topics might turn up in the interviews. Within the self-study phases the students worked in groups preparing the questionnaires and conducting the interviews with the migrants. The educator was available for questions via the universities' online-platform either in a personally (email) or publicly (forum). The following on-campus class was dedicated to presentations of interview results and discussion. The educator adopted the role of a coach in this phase, asking questions, leading students through the process and summarizing the results. Then again students worked on the second task by commenting on a controversial text on intercultural topics within their group and preparing a set of language patterns, like commenting, interpreting, arguing and describing. By using these patterns, the students gained insight into diverse thinking processes that turned out to be very essential. Moreover, they acquired the ability for metacognition not only on the text itself but also via the use of language. The challenge was to structure 
these thoughts in writing. Again the students received feedback on their language patterns in the virtual classroom. It was interesting that the students had difficulties in separating interpretations made in the text from their own interpretations, crucial point for metacognition. However, once this topic was made clear, students wrote essays with a clear separation of thoughts. Many of them liked having feedback on their essays via the online platform before handing them in. So in contrast to the old format, students were very much engaged in their learning, the mixture of the didactical formats guaranteed variety; they could fulfill their tasks more or less at their own pace, did collaborative work in groups and - by the way - learned how to think critically by interviewing people and commenting on controversial texts.

\section{Diverse roles of the educator}

What turned out to be essential to succeed within this model was the ability of the educator to change roles. According to Döring (2000) the three phases of oncampus classes, self-study periods and online learning (including virtual classrooms) can be separated into the two paradigms of traditional teaching and problem solving, so in sum six learning environments emerge. According to this structure, the course applied the following settings: on-campus class/training; on-campus class/problem solving, virtual classroom and online feedback/problem solving, selfstudy periods/problem solving; starting from the training to self-paced and selfdirected learning, recommended for psychological topics.

The learning settings go along with the diverse roles the educator had to assume. Although the traditional role of an educator as a teacher who gives broadcast lectures (Khan, 2013) decreases, this is still essential for certain parts of a course. This role goes along with the ability to give clear explanations on the contents and tasks. Students, nevertheless, need the structure and objectives of the course. Framing the contents is a clear requirement of this role. Moreover, the educator has to be able to represent a coach, guiding and leading the students through the learning process. When dealing with psychological topics, it is of advantage if the teacher holds a psychological or coaching degree to handle whatever may occur during the process. The educator cannot rely only on his/her knowledge, but has to stimulate learning processes through personal integrity. "The respect towards teachers is related to competence and experience instead of status and power, so the hierarchy in the class will be dismissed in favor of interconnectivity between all participants involved in the process." (online, Hauptfeld, 2016) In this role it is essential how capable the educator is when giving feedback. The use of his/her language may determine the relationship with students to a huge extent. Feedback should not be too harsh and not too soft and its phrasing is essential. Concerning the virtual classroom, the educator has to be able to handle the technical issues together with the didactical tools and tasks given to the students in the role of a moderator. Moderation means asking questions, stimulating discussion, giving comments and paraphrasing and summarizing different points of view. According to these three roles, it is essential for a successful course to choose the tasks carefully and arrange the learning settings in a way that best fit the three phases.

\section{Characteristics of virtual classrooms}

Virtual classroom teaching is fun and intensive work. Although technology-based education is already widespread, some educators have a reserve against it that may go together with the changing of roles, fear of technology and time consuming preparation. Teaching in virtual classrooms requires other skills and competencies than those in traditional teaching and the tasks have to be chosen properly as online 
communication has to be initialized; the design of the communication as well as the interaction within learning processes is a vital didactical part (Ojsterek, N. et al, 2010, translated by $\mathrm{PH}$ ).

Educators are in the role of a moderator, structuring the learning contents via technology. According to Ojsterek et al (2010:186) the tasks have to be meaningful for recent and future situations; the student groups have to take on responsibility and should present a result within the virtual classroom; moreover they have to get familiar with the technology. This meant elaborating carefully on the topics and tasks chosen for the virtual part of the course. We decided to give feedback on essential parts of the course online, the preparation of the questionnaire and the language patterns, in order to give students the chance to reflect on their work and not so much on personal matters at this stage of the process.

The technical functions structured the "teaching" to a huge extent. Teachers and students are able to share documents and comment on them. Personal discretion has to be guaranteed. Students asked if the other participants are able to hear them while speaking with the teacher. No function exists to turn this off, so the teacher had to provide security by suggesting that only those topics that may be public are discussed in the group, always taking into account that learning processes via the internet become public (Kerres, 2006, in Ojsterek et al 2010). In contrast to oncampus training, the student who is speaking has the full attention of the others. On the one hand, this causes fear at the beginning when they are not used to it; on the other hand it fosters personal contact because of the strong one-to-one attention in communication. Moreover, the contents can be structured by the muting function. The students can still hear each other, but the teacher only hears the student when speaking with him/her. This allowed an utmost concentration, not given in class. It turned out that the time could be used more efficiently than in class. If the muting function is turned off, the teacher hears all the students. This represents a classroom feeling but students have to be disciplined in this case (depends on the size of the group). So the educator was able to structure the virtual classroom via technical functions to a huge extent.

Because of the strong one-to-one-attention during speaking, the relationship between the educator and the student turned out to be stronger. Döring (2000) summarizes the advantages of virtual classrooms by enhancing self-directed learning, fostering communication between teachers and students, optimizing their performance and increasing satisfaction with the results. Indeed, it turned out in the next on-campus training that the teacher-student relationship had somewhat intensified, because "there is a tendency that participants of virtual classrooms feel more involved within the educational process; they appreciate the exchange of homework between the students and noticing closer contact to the educator" (Döring, 2000:465, translated by PH). Even when discussing crucial topics, the physical distance provides security, as students know that they will be heard when commenting in an inadequate way. So this problem did not occur in virtual classrooms, in contrast to on-campus classes where students turn around and give inappropriate comments. Another advantage is control over tempo. The tempo can be easily adjusted, a second meeting can be agreed on and students are not forced to be concentrated $100 \%$ during the online classroom. Positively speaking this means that they feel relief from showing or simulating interest all the time in campus classes. Virtual classrooms give the chance for individual settings. 


\section{Communication in on-campus classes}

In contrast to virtual classrooms, when starting the course and summarizing the results, on-campus classes were preferred. The educator adopted the role of a classical teacher in the first class and the one as a coach in the second class when discussing the results. Mazur was the first who developed a strategy called peer instruction, published in 1997 when the Inverted Classroom Model also emerged. He favored the approach of coaching students in class instead of teaching excathedra. Especially in the second class, the individualized coaching approach from the virtual classrooms continued. The teacher gave feedback on the presentations; the students discussed the topics that emerged from all the interviews. "Learning" within this context does not mean recapitulating information anymore but arranging the information gained by the interviews, in a personally meaningful way and reflecting on it. If knowledge and meaning are constructed in class, the roles of students and teachers change in the way of a more equal and less hierarchical teaching. Consequently this approach considers the personality of the students "the constructivist model places students at the center of the process" (King, 1993:30). This approach fits best for teaching psychological topics. Who else if not students are in the center of the learning process? Teachers in this case should see themselves in the role of making offers to the students. It is then their responsibility to take or leave it. This places the student in the center of the action, being in full command of the learning process and defining what "knowledge", "thinking", metacognition" will mean to them in the future when leading a team, department or even company.

\section{Discussion and conclusion}

Technology can only assist teaching processes, never replacing personal contact. Part-time students themselves consider online classes more a necessity than a valuable add-on to their studies. As a result, educators have to be very clear about their applied teaching methods. Especially the on-to-one attention in virtual classrooms, assuming it is integrated well, would appear to be a circumstance that can enhance the quality of education. This works best in a virtual group with a size of approximately 15 students. When it comes to psychological topics where the personality of the students is involved, this function of technology may intensify teaching and learning processes, providing that the students feel safe within their environment and that the educator is able to moderate the process in a clear language without any harsh feedback or commands. Moreover, the topics of teaching have to be combined with the needs and environment of the students who bring with them various experiences and attitudes from their workplace. In order to answer the research question of how we could redesign the course according to the needs of the students and the requirements of the curriculum, we decided to concentrate on the topics of leadership in intercultural situations that naturally involve critical thinking for successful communication and lead students to the process of metacognition by reflecting on their own behavior.

\section{References}

1. Döring, N. (2000), "Lernen und Lehren im Internet", in Batinic, B. (Ed.), Internet für Psychologen, 2. Auflage, Nürnberg, Hogrefe, S., pp. 443-477.

2. Dräger, J., Müller-Eiselt R. (2015), Die Digitale Bildungsrevolution, Der radikale Wandel des Lernens und wie wir ihn gestalten können, München, DVA

3. Hauptfeld, P. (2016), Five ways the lecture halls of 2030 will be different, available at: https://www.timeshighereducation.com/news/european-association-for- 
international-education-eaie-conference-2016-five-ways-the-lecture-halls-of-2030-willbe-different (30 April 2017)

4. Khan, S. (2013), The One World Schoolhouse, Education Reimagined, New York, Hachette Book Group.

5. King, A. (1993), "From Sage on the Stage to Guide on the Side", College Teaching, Vol. 4, pp. 30-35.

6. Mazur, E. (1997), Peer Instruction, A User's Manual, Upper Saddle River, NJ, Prentice Hall, Series in Educational Innovation.

7. Ojsterek, N., Adamus, T. (2010), Kollaborative Wissenskonstruktion in virtuellen Welten: Anforderungen an die Gestaltung von Lernaufgaben, in Hug, T., Maier, r. (Hg.), Medien - Wissen - Bildung, Explorationen visualisierter und kollaborativer Wissensräume, Innsbruck, Innsbruck University Press, S., pp. 177-197.

\section{About the author}

Dr. Petra Hauptfeld is a professor at the University of Applied Sciences Burgenland in the Department Business Studies with special expertise in language teaching, academic writing, intercultural communication and organizational leadership. She graduated in German Studies and Communication Sciences from the University of Salzburg (1989) and Vienna (2003). She is an expert in international project management and conducted the two year EU project AWO - Academic Writing Online (2014 - 2016). She has published a number of scientific papers in international and national journals and participated in many conferences on future teaching and technological education, her recent areas of research. Author can be contacted at petra.hauptfeld@fh-burgenland.at. 